\title{
Costs and benefits of induced resistance in a clonal plant network
}

\author{
Sara Gómez • Vít Latzel · Yolanda M. Verhulst • \\ Josef F. Stuefer
}

Received: 18 August 2006/Accepted: 4 June 2007/Published online: 3 July 2007

(C) Springer-Verlag 2007

\begin{abstract}
Plant defense theory suggests that inducible resistance has evolved to reduce the costs of constitutive defense expression. To assess the functional and potentially adaptive value of induced resistance it is necessary to quantify the costs and benefits associated with this plastic response. The ecological and evolutionary viability of induced defenses ultimately depends on the long-term balance between advantageous and disadvantageous consequences of defense induction. Stoloniferous plants can use their inter-ramet connections to share resources and signals and to systemically activate defense expression after local herbivory. This network-specific early-warning system may confer clonal plants with potentially high benefits. However, systemic defense induction can also be costly if local herbivory is not followed by a subsequent attack on connected ramets. We found significant costs and benefits of systemic induced resistance by comparing growth and performance of induced and control plants of the stoloniferous herb Trifolium repens in the presence and absence of herbivores.
\end{abstract}

Keywords Adaptive plasticity hypothesis - Physiological integration · Plant communication - Plant defense .

Trifolium repens

S. Gómez $(\bowtie)$ · Y. M. Verhulst · J. F. Stuefer

Department of Ecology, Radboud University Nijmegen,

Toernooiveld 1, 6525 ED Nijmegen, The Netherlands

e-mail: S.Gomez@science.ru.nl

V. Latzel

Institute of Botany, Academy of Sciences of the Czech Republic,

Třeboň, Czech Republic

\section{Introduction}

Plants can allocate a limited pool of resources to the three main functions of growth, reproduction and defense, suggesting that increased investments in one function may compromise the others. Empirical studies have shown that constitutive defense can be costly (e.g., tannins, Sagers and Coley 1995; glandular trichomes, Elle et al. 1999). Plant defense theory postulates that inducible defense mechanisms have evolved to reduce these costs by optimizing the temporal match between resource investment into defense and herbivory threats (Herms and Mattson 1992; Agrawal et al. 1999). In the last decades numerous studies have attempted to find costs of induced defense (reviewed in Bergelson and Purlington 1996 and Strauss et al. 2002) but evidence for costs of inducible plant defense remains scarce and inconclusive. More recently, empirical evidence has emerged supporting the allocation cost theory with the help of improved experimental designs, genetic engineering, and biochemical methodology (Baldwin 1998; Van Dam and Baldwin 1998, 2001; Heil and Baldwin 2002).

Inducible resistance is a form of phenotypic plasticity as it allows plants to express an adequate phenotype in response to temporally and spatially variable herbivore damage. Herbivore-induced changes in the phenotypes of plants often relate to trait alterations which reduce the palatability and digestibility of consumed tissue by producing toxic metabolites and/or by up-regulating the production of a variety of defensive compounds. The ecological viability of induced resistance as an efficient defense strategy depends on the balance of costs and benefits associated with plastic defense induction. Assessing the benefits of induced defense in conjunction with possible costs is a prerequisite for estimating the advantages and disadvantages of plastic defense induction as a 
potentially adaptive form of phenotypic plasticity (Dudley and Schmitt 1996; Schmitt et al. 1999) and hence for understanding potential selection pressures leading to the evolution of induced plant defenses (Agrawal 2000).

Costs of defense have been traditionally measured in terms of decreased plant fitness. Allocation costs refer to a direct fitness decrease as a consequence of resource-mediated trade-offs between defense investment and other plant functions. Recent empirical and conceptual work has provided convincing arguments for the notion that defense induction can also affect fitness in an indirect manner, via a multitude of potentially complex ecological interactions (Van Dam and Baldwin 1998, 2001; Heil and Baldwin 2002; Strauss et al. 2002). These costs are commonly referred to as ecological costs.

Allocation theory suggests that costs of plastic defense induction should be more apparent in low-resource environments than under optimal growth conditions (Herms and Mattson 1992; Bergelson 1994; Bergelson and Purlington 1996; but see van Dam and Baldwin 2001) as the diversion of resources to defense can not easily be compensated for by enhanced resource acquisition. In addition, experiments to detect costs of defense conducted under quasi-optimal conditions are unlikely to reflect realistic situations, and therefore, tend to underestimate plasticity costs. To overcome this problem, several studies have used competitive and/or low-resource environments to quantify costs of induced defense (Siemens et al. 2003 and studies quoted therein). Additionally, previous studies have shown that controlling the genetic background of plants can substantially enhance the chances to detect costs, by removing confounding effects due to genetic variation in the induced response (Bergelson and Purlington 1996; Strauss et al. 2002).

Stoloniferous plants consist of multiple, genetically identical individuals (ramets) that are interconnected by aboveground horizontal stems (stolons). Resource transport within clonal plant networks has been extensively described in the literature (Pitelka and Ashmun 1985; Marshall 1990; Alpert 1996; Alpert and Stuefer 1997). Nevertheless, the importance of stolon connections for the transport of defense agents is a novel aspect (Stuefer et al. 2004) that has only recently been demonstrated (Gómez and Stuefer 2006). Ramets of the stoloniferous herb Trifolium repens are able to systemically induce other ramets after local herbivore damage. On the one hand, this form of physiological integration may confer clonal plant networks with considerable benefits by allowing for a fast, specific and efficient early-warning system among interconnected ramets. On the other hand, the potentially large spatial scale of clonal plant networks may also lead to substantial costs if network members become induced without being threatened by herbivores (Gómez and Stuefer 2006). These costs are due to a potential mismatch in the spatio-temporal scale of plastic defense expression and the dynamics and patterns of herbivore attacks.

To assess the potentially adaptive nature of plastic responses, "it is necessary to demonstrate that the phenotype induced in each relevant environment confers higher fitness in that environment relative to alternative phenotypes" (Schmitt et al. 1999). This is analogous to stating that the induced phenotype should incur costs in herbivore-free environments, while defense induction should lead to benefits in herbivore-exposed environments. To quantify costs and benefits we measured traits related to plant fitness and performance of induced and uninduced $T$. repens plants in the absence and presence of herbivores. Growing induced and uninduced plants in the absence of herbivores allows for a quantification of possible costs of induced resistance, simulating localized damage (e.g., by small herbivores with a low mobility) and the activation of defense in ramets beyond the feeding range of the herbivore. Benefits of induction, however, can only be assessed in the presence of herbivores after an initial attack, thereby simulating a scenario with mobile herbivores showing active foraging behavior beyond the first place of attack.

In this study we tested the following specific hypotheses:

1. In the absence of herbivores, systemically induced ramets of clonal plants perform worse than uninduced ramets of the same genotype. This is due to costs of defense induction when defense is not needed.

2. In the presence of herbivores, induced ramets of clonal plants perform better than uninduced plants, due to an enhanced protection through induced defense.

To test these hypotheses we grew induced and uninduced (control) plants of the stoloniferous herb T. repens together to expose them to mutual competitive interactions, resembling sub-optimal growing conditions in a sward. To quantify costs and benefits of induced resistance we grew plants in herbivore-free and herbivore-exposed environments, respectively.

\section{Materials and methods}

\section{Study organisms}

Five genotypes of the stoloniferous herb T. repens $\mathrm{L}$. were vegetatively propagated in a greenhouse at a mean temperature of $21^{\circ} \mathrm{C} / 19^{\circ} \mathrm{C}$ (day/night), and at a $16 \mathrm{~h} / 8 \mathrm{~h}$ (light/ dark) photoperiod. The genotypes originated from natural riverine grassland populations situated along the river Waal, The Netherlands. They had been collected 4 years 
prior to the start of this experiment and were grown under common garden conditions, eliminating possible maternal and environmental carry-over effects.

The beet armyworm (Spodoptera exigua Hübner) used in this study is a generalist caterpillar with a broad host range. The caterpillar colony was maintained at a constant temperature of $24^{\circ} \mathrm{C}$ and $16 \mathrm{~h} / 8 \mathrm{~h}$ (light/dark) photoperiod. The larvae were reared on an artificial diet described in Biere et al. (2004).

Pre-growth of plant material

We started the experiment with 64 cuttings of each of the five genotypes. The cuttings were planted in pairs in plastic trays $(16 \mathrm{~cm} \times 12 \mathrm{~cm} \times 5 \mathrm{~cm})$ using sterilized clay grains as a substrate (Seramis; Masterfoods, Germany). Each tray was fertilized weekly with $50 \mathrm{ml}$ full-strength Hoagland solution before the start of the experiment. At the beginning of the experiment, all cuttings consisted of a main stolon with at least eight fully developed ramets. If present, side branches were removed immediately before starting the experiment.

Costs
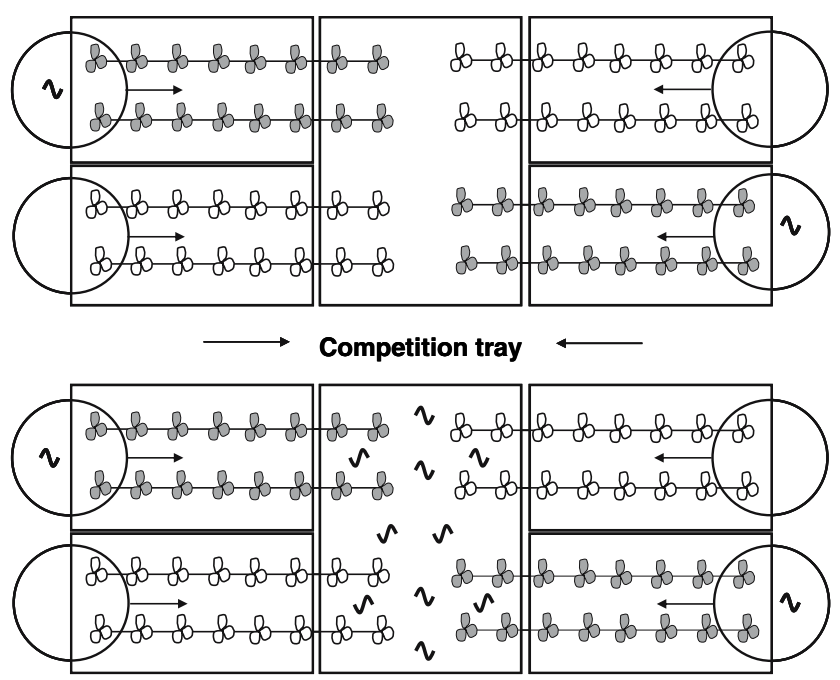

Benefits

Fig. 1 Schematic representation of the experimental set-up to measure costs and benefits of systemic induced resistance (SIR) in a clonal plant network. Control (white) and defense-induced (gray) plants grew from four peripheral trays into a common, central competition tray. The circles represent petri dishes used for a continued controlled herbivore attack (defense induction treatment). To measure costs of SIR, plants grew together in the absence of herbivores in the competition tray (upper drawing). To measure benefits, ten caterpillars (wavy black lines) were added to the competition tray (lower drawing). See Materials and methods for more details

\section{Experimental design}

The experimental set-up (Fig. 1) to measure costs and benefits of systemic induced resistance (SIR) consisted of four peripheral trays placed around a central tray, which we will refer to as the "competition tray". All trays were of similar dimensions $(16 \mathrm{~cm} \times 12 \mathrm{~cm} \times 5 \mathrm{~cm})$. Each of the peripheral trays contained two cuttings with at least eight ramets each. The cuttings in two of those trays received a treatment to induce defense during the entire duration of the experiment (for details see below), while the cuttings in the other two trays remained uninduced (control). Trays receiving the same treatment were placed diagonally opposite each other. The competition tray was placed inside a metal frame $(20 \mathrm{~cm} \times 15 \mathrm{~cm} \times 20 \mathrm{~cm})$ covered by mosquito netting (mesh gauge $0.2 \mathrm{~cm}^{2}$ ) with four small openings on both longitudinal sides. The two youngest ramets of each cutting were inserted through the mesh openings and allowed to grow (proliferate and root) in the competition tray for 19 days. We used five $T$. repens genotypes, each of which was replicated 4 times to measure costs and 4 times to measure benefits of defense induction. All induced and control plants grown together in the same experimental set-up (as described above) belonged to the same genotype. The experimental systems were randomly distributed on greenhouse benches.

\section{Systemic induction of resistance}

Systemic induction of resistance was achieved through a controlled herbivore attack. One $S$. exigua larva was confined with two leaves in one petri dish mounted on the plants (Gómez and Stuefer 2006). The corresponding ramets of uninduced control plants were similarly enclosed in modified petri dishes but without adding any larvae. The controlled herbivore attack was maintained throughout the course of the experiment, starting on the ramet on the eighth position (counting from the tip of the stolon) from each cutting. When the two ramets inside the petri dish had lost at least $50 \%$ of leaf tissue, the petri dish was moved forward on the stolon and the adjacent, younger ramet was inserted into the petri dish. Whenever the induction treatment was moved forward on the induced cuttings, a comparable leaf area was removed with scissors from one ramet of each cutting in the control trays. This was done to compensate for the leaf area loss due to caterpillar feeding in the induced plants. Cutting the leaves with scissors does not induce resistance in $T$. repens (S. Gómez, unpublished data). The induction treatment started 1 day after the cuttings were placed into the competition tray. If the caterpillar inside the petri dish died, it was replaced by a new one to maintain defense induction. 
In order to enhance plant interactions, induced and control plants were grown together in the competition tray. Since all plants growing together belonged to the same genotype, induction effects cannot be confounded with genetic differences in plant traits, including competitive ability, between induced and control plants. All measurements described below were performed on ramets growing in the competition trays.

\section{Costs of SIR}

Costs of defense induction were measured as a reduction in plant performance. Costs can be measured after initial herbivore damage (and consequent defense induction) in the absence of subsequent herbivore attacks. To quantify costs of defense induction we measured the following traits which are known to be closely related to plant performance and fitness: total biomass production, relative biomass allocation to leaves, petioles, stolons, and roots, number and length of the main and side stolons and number of ramets on the main and side stolons. We also measured the petiole length, petiole dry mass, leaf area, leaf dry mass of the fourth and fifth youngest ramets of each cutting.

\section{Benefits of SIR}

To quantify benefits of SIR we exposed the plants in the competition tray to a second, controlled herbivory attack (referred to as "herbivory treatment"). We released five fourth instar caterpillars on day 16 in the competition tray and then added two and three more on day 17 and 18, respectively, to achieve substantial levels of herbivore damage. The plants were harvested 19 days after the start of the experiment. We quantified benefits of induced resistance by scoring herbivory damage in the induced and in the control plants. At the time of harvesting each ramet on the main stolon was classified according to the leaf area consumed. We visually estimated the damage and assigned each ramet a damage category ranging from 0 to 3 . The values corresponded to the following amounts of damage: $0=$ no damage, $1=1-33 \%, 2=33-66 \%$ and $3=66-$ $100 \%$ of leaf area consumed. We also recorded the position of the damaged ramet on the stolon to investigate possible intra-clonal variation in the damage pattern according to ramet age. In addition to the degree of damage, we measured the dry mass of leaves, petioles, stolons and roots in induced and control plants.

Herbivore preference test

One day before releasing the caterpillars (herbivory treatment) we performed two dual choice tests per competition tray to check whether plants assigned to the defense-induction treatment were systemically induced. For each competition tray we cut off two control and two induced ramets of a similar developmental stage (thirdyoungest fully expanded leaf). Each control ramet was paired with an induced one and placed together on a moist filter paper in a petri dish to perform a dual choice test. A fourth instar $S$. exigua caterpillar was placed in the middle and allowed to feed until more than $30 \%$ of one of the leaves was consumed or for $48 \mathrm{~h}$. By means of visual estimates the leaf with the largest area consumed was recorded for each choice test. In $78 \%$ of the cases more of the control leaf was consumed (sign test $M=23, P<0.0001$; $n=77$ ) than the induced one, confirming that plants in the competition trays that had received local herbivore damage (defense induction treatment) were induced before the herbivory treatment started.

\section{Statistical analysis}

Central competition trays were considered the units of replication in all statistical analyses. To avoid pseudoreplication and a consequent inflation of $d f$ (Hurlbert 1984), all traits measured on plants (cuttings) in the competition trays were pooled per treatment (by averaging the four control cuttings and the four defense-induced cuttings, respectively) prior to data analysis. Consequently, our experiment had 20 replicates for measuring costs and 20 replicates for assessing benefits. Competing plants cannot be considered independent from each other as, by definition, they change each other's environment, growth and development. To take this dependence into account we used a repeated measures design to analyze differences between competing plants that belonged to different treatment groups. Repeated measures analysis explicitly considers intrinsic relationships between treatment groups (Potvin et al. 1990).

\section{Costs of SIR}

Repeated measures ANOVA was performed to test for costs of defense induction in number and length of the main and side stolons and number of ramets on the main and side stolons, relative biomass allocation to roots, stolons, petioles and leaves and petiole length, petiole dry mass, leaf area, leaf dry mass of the fourth and fifth youngest ramets. Defense induction (induced vs. control) was considered a within-subjects effect, and genotype was treated as a between-subjects effect. Absolute dry masses of roots, stolons, petioles and leaves were analyzed using two-way repeated measures ANOVA (within-subjects effect-defense induction; between-subjects effects-plant genotype and herbivory). 


\section{Benefits of SIR}

The amount of damage in the herbivory treatment was assessed with doubly repeated measures ANOVA using ramet age and defense induction as repeated factors and genotype as main effect. The analysis included a profile analysis (SAS procedure GLM; profile statement) to test for differences in the degree of damage between adjacent ramets on the stolons. To correct for differences in the developmental stage of different cuttings we used only the six youngest ramets of each cutting in the damage analysis. All analyses were conducted with SAS 9.1 (SAS Institute, Cary, N.C.).

\section{Results}

\section{Costs of SIR}

Total dry mass did not differ between control and induced plants (Table 1). However, defense induction caused a significant reduction in petiole dry mass. Additionally, defense induction resulted in a shift in biomass allocation to the different plant parts. Relative biomass allocation to leaves increased significantly after defense induction (Table 2; $P=0.01)$. The percentage of biomass allocated to roots, stolons and petioles did not significantly differ between control and induced plants. (Table 3)

The number of ramets produced on the main stolon was $7 \%$ lower in induced as compared to control plants (Table 4; induction effect $P=0.003$ ). The number and length of side stolons and the number of ramets formed on them did not change after defense induction.
The fourth and fifth youngest ramets on the main stolon produced petioles $5 \%$ shorter in the induced plants (Table 4; fourth ramet $P=0.03$, fifth ramet $P=0.07$ ). Leaf area, leaf dry mass and petiole dry mass measured on those ramets were not significantly affected by the induction treatment.

\section{Benefits of SIR}

Defense induction had a very strong effect on the amount of damage inflicted by $S$. exigua larvae on the plants (Table 5; induction effect $P<0.0001$; Fig. 2). The number of ramets that were partially or fully consumed during the herbivore attack was consistently higher in control than in induced plants. Most of the damaged ramets lost only a small part of their leaf area (1-5\%). This was consistent for both control and induced plants (Fig. 2). In induced plants up to $44 \%$ of the ramets on the main stolon were not damaged, whereas in control plants only $22 \%$ of ramets on the main stolon were undamaged.

The herbivory treatment significantly reduced the biomass of leaves and petioles (Table 1; $P=0.049$ and $P=0.036$, respectively; Table 3 ) in both induced and uninduced plants. In the presence of herbivores, induced and uninduced plants had a comparable total biomass. However, induced plants showed a larger percentage of biomass in their leaves (Table 3; repeated measures ANOVA; $F=17.44 P=0.0008$ ), suggesting that the induced plants benefitted from increased relative biomass in those organs under attack.

Ramet age, regardless of the induction state, had a very strong effect on herbivore preference (Table 5; age effect $P<0.0001)$. Younger ramets, especially the first and sec-

Table 1 Repeated measures ANOVA for effects of genotype, herbivory and defense induction on roots, stolons, petioles, leaves and total dry mass

\begin{tabular}{|c|c|c|c|c|c|c|c|c|c|c|c|}
\hline \multirow[t]{2}{*}{ Source } & \multirow[t]{2}{*}{$d f$} & \multicolumn{2}{|l|}{ Root } & \multicolumn{2}{|l|}{ Stolon } & \multicolumn{2}{|c|}{ Petioles } & \multicolumn{2}{|l|}{ Leaves } & \multicolumn{2}{|l|}{ Total } \\
\hline & & MS & $F$ & MS & $F$ & MS & $F$ & MS & $F$ & MS & $F$ \\
\hline \multicolumn{12}{|c|}{ Between-subject effects } \\
\hline Genotype (Gen) & 4 & 981 & $7.20 * * *$ & 3,710 & $4.12 * * *$ & 3,741 & $10.97 * * *$ & 11,002 & $10.85 * * *$ & 60,377 & $8.99 * * *$ \\
\hline Herbivory (Herb) & 1 & 28.1 & 0.21 & 78.6 & 0.09 & 1,646 & $4.83 *$ & 4,234 & $4.18^{*}$ & 11,926 & 1.78 \\
\hline Gen $\times$ Herb & 4 & 49.3 & 0.36 & 124 & 0.14 & 105 & 0.31 & 292 & 0.29 & 1,171 & 0.17 \\
\hline Error & 30 & 136 & & 899 & & 342 & & 1,014 & & 6,714 & \\
\hline \multicolumn{12}{|c|}{ Within-subject effects } \\
\hline Induction (Ind) & 1 & 79.8 & 0.81 & 574 & 1.97 & 416 & $5.11 *$ & 98.6 & 0.37 & 1,879 & 0.99 \\
\hline Ind $\times$ Gen & 4 & 53.9 & 0.54 & 83.1 & 0.28 & 50.7 & 0.62 & 367 & 1.37 & 1,054 & 0.55 \\
\hline Ind $\times$ Herb & 1 & 106 & 1.07 & 57.1 & 0.20 & 11.1 & 0.14 & 160 & 0.60 & 1,143 & 0.60 \\
\hline Ind $\times$ Gen $\times$ Herb & 4 & 139 & 1.40 & 542 & 1.86 & 159 & 1.95 & 265 & 0.99 & 3,525 & 1.85 \\
\hline Error & 30 & 99.0 & & 292 & & 81.3 & & 268 & & 1,901 & \\
\hline
\end{tabular}

$* 0.01<P<0.05, * * * P<0.0001$ 
Table 2 Costs of systemic induced resistance (SIR). Repeated measures ANOVA for effects of genotype and defense induction on relative dry mass allocation to roots, stolons, petioles and leaves on plants without an herbivory treatment in the competition tray

\begin{tabular}{|c|c|c|c|c|c|c|c|c|c|}
\hline \multirow[t]{2}{*}{ Source } & \multirow[t]{2}{*}{$d f$} & \multicolumn{2}{|c|}{ Roots } & \multicolumn{2}{|c|}{ Stolons } & \multicolumn{2}{|c|}{ Petioles } & \multicolumn{2}{|c|}{ Leaves } \\
\hline & & MS & $F$ & MS & $F$ & MS & $F$ & MS & $F$ \\
\hline \multicolumn{10}{|c|}{ Between-subjects effects } \\
\hline Genotype (Gen) & 4 & 29.8 & $6.61 * *$ & 496 & $14.57 * * *$ & 22.7 & $3.54 *$ & 35.7 & $7.3 * *$ \\
\hline Error & 15 & 4.5 & & 127 & & 6.4 & & 4.9 & \\
\hline \multicolumn{10}{|c|}{ Within-subject effects } \\
\hline Induction (Ind) & 1 & 12.0 & 2.06 & 0.04 & 0.01 & 5.3 & 1.92 & 35.8 & $7.32 *$ \\
\hline Ind $\times$ Gen & 4 & 2.2 & 0.38 & 8.2 & 1.16 & 1.8 & 0.64 & 10.9 & 2.24 \\
\hline Error & 15 & 5.8 & & 7.1 & & 2.8 & & 4.9 & \\
\hline
\end{tabular}

$* 0.01<P<0.05, * * 0.001<P<0.01, * * * P<0.0001$

Table 3 Average $( \pm$ SE) absolute and relative dry mass allocated to roots, stolons, petioles and leaves of uninduced and induced plants in the absence of a subsequent herbivory treatment (Costs) and in the presence of a subsequent herbivory treatment (Benefits) in the competition tray

\begin{tabular}{llllll}
\hline & Root $(\mathrm{mg})$ & Stolons $(\mathrm{mg})$ & Petioles $(\mathrm{mg})$ & Leaves $(\mathrm{mg})$ & Total $(\mathrm{mg})$ \\
\hline Costs & & & & & \\
Uninduced & $15.6 \pm 3.0(4.5 \pm 0.7 \%)$ & $103.2 \pm 6.7(34.9 \pm 1.0 \%)$ & $72.6 \pm 4.8(24.9 \pm 0.6 \%)$ & $107.5 \pm 8.3(35.7 \pm 0.7 \%)$ & $298.9 \pm 21.1$ \\
Induced & $11.3 \pm 2.1(3.4 \pm 0.6 \%)$ & $96.1 \pm 6.0(34.8 \pm 1.0 \%)$ & $67.3 \pm 4.5(24.2 \pm 0.5 \%)$ & $106.8 \pm 8.3(37.6 \pm 0.6 \%)$ & $281.6 \pm 19.1$ \\
Benefits & & & & & \\
Uninduced & $14.5 \pm 2.2(5.1 \pm 0.8 \%)$ & $99.5 \pm 4.8(37.6 \pm 0.8 \%)$ & $62.8 \pm 3.7(23.8 \pm 0.8 \%)$ & $90.1 \pm 5.6(33.5 \pm 0.8 \%)$ & $266.9 \pm 13.2$ \\
Induced & $14.8 \pm 3.7(4.8 \pm 0.9 \%)$ & $95.8 \pm 6.1(36.8 \pm 1.1 \%)$ & $59.0 \pm 4.5(22.6 \pm 0.6 \%)$ & $95.1 \pm 7.6(35.8 \pm 0.6 \%)$ & $264.7 \pm 19.7$ \\
\hline
\end{tabular}

Table 4 Costs of SIR. Repeated measures ANOVA for effects of genotype and defense induction on plant fitness and performance-related traits in the absence of herbivores

\begin{tabular}{|c|c|c|c|c|c|c|c|c|c|c|c|c|c|c|c|}
\hline \multirow[t]{2}{*}{ Source } & \multirow[t]{2}{*}{$d f$} & \multicolumn{2}{|c|}{$\begin{array}{l}\text { Ramet no. main } \\
\text { stolon }\end{array}$} & \multicolumn{2}{|c|}{$\begin{array}{l}\text { Length main } \\
\text { stolon }\end{array}$} & \multicolumn{2}{|c|}{$\begin{array}{l}\text { Ramet no. side } \\
\text { stolons }\end{array}$} & \multicolumn{2}{|c|}{$\begin{array}{l}\text { Length side } \\
\text { stolons }\end{array}$} & \multicolumn{2}{|c|}{$\begin{array}{l}\text { Side stolons } \\
\text { number }\end{array}$} & \multicolumn{2}{|c|}{$\begin{array}{l}\text { Fourth ramet } \\
\text { petiole length }\end{array}$} & \multicolumn{2}{|c|}{$\begin{array}{l}\text { Fourth ramet } \\
\text { area }\end{array}$} \\
\hline & & MS & $F$ & MS & $F$ & MS & $F$ & MS & $F$ & MS & $F$ & MS & $F$ & MS & $F$ \\
\hline \multicolumn{16}{|c|}{ Between-subjects effects } \\
\hline Genotype (Gen) & 4 & 2.38 & $3.41 *$ & 23.5 & $5.4 * * *$ & 71.9 & $6.72 * *$ & 30.8 & 1.63 & 16.0 & $12.97 * * *$ & 18.0 & $14.93 * * *$ & 8.57 & $15.36 * * *$ \\
\hline Error & 15 & 0.69 & & 4.31 & & 10.7 & & 18.9 & & 1.23 & & 1.20 & & 0.55 & \\
\hline \multicolumn{16}{|c|}{ Within-subject effects } \\
\hline Induction (Ind) & 1 & 1.80 & $12.13 * *$ & 7.57 & 2.45 & 1.25 & 0.25 & 0.78 & 0.23 & 0.15 & 0.31 & 4.38 & $5.22 *$ & 0.10 & 0.23 \\
\hline Ind $\times$ Gen & 4 & 0.17 & 1.19 & 3.92 & 1.27 & 1.83 & 0.37 & 4.10 & 1.22 & 0.12 & 0.24 & 0.35 & 0.42 & 0.09 & 0.21 \\
\hline Error & 15 & 0.14 & & 3.08 & & 4.95 & & 3.37 & & 0.51 & & 0.84 & & 0.46 & \\
\hline
\end{tabular}

$* 0.01<P<0.05, * * 0.001<P<0.01, * * * P<0.0001$

ond youngest ones, were heavily preferred over older ones (profile analysis; Fig. 2). The first ramet exhibited particularly severe damage in both induced and control plants (average leaf area consumed $>65 \%$; Fig. 2).

Defense induction had a significant effect on leaf area loss due to herbivory in all ramet age classes (Fig. 2). The degree to which systemic defense induction reduced herbivory damage was similar for ramets of all age classes (Table 5; no age $\times$ induction effect). There was a marginally significant genotype effect on the feeding of the caterpillars (Table 5; genotype effect $P=0.09$ ).

\section{Discussion}

Our study provides empirical evidence of significant costs and benefits of SIR in a clonal plant network. In agreement with our hypotheses, induced and control plants showed clear differences in performance and fitness-related traits when grown in the absence and presence of herbivores. In environments without herbivores, induced plants produced fewer ramets, shorter petioles and exhibited a shift in biomass allocation patterns. In environments with herbivores, control plants suffered consistently higher degrees of 
Table 5 Benefits of SIR. Doubly repeated measures ANOVA for effects of genotype, defense induction and ramet age on leaf area loss due to herbivory

\begin{tabular}{llll}
\hline Source & $d f$ & MS & $F$ \\
\hline Between-subjects effects & & & \\
Genotype (Gen) & 4 & 1,102 & $2.39 \dagger$ \\
Error & 15 & 461 & \\
Within-subjects effects & & & \\
Induction (Ind) & 1 & 6,847 & $63.92^{* * *}$ \\
Ind $\times$ Gen & 4 & 244 & 2.28 \\
Error (induction) & 15 & 107 & \\
Age & 5 & 18,988 & $133.0 * * *$ \\
Age $\times$ Gen & 20 & 630 & $4.41 * * *$ \\
Error (age) & 75 & 142 & 1.22 \\
Ind $\times$ Age & 5 & 125 & $1.67 \dagger$ \\
Ind $\times$ Age $\times$ Gen & 20 & 172 & \\
Error (Ind $\times$ Age) & 75 & 103 & \\
\hline
\end{tabular}

$\dagger 0.1>P>0.05, * * * P<0.0001$

leaf damage than induced plants. Even though defense induction resulted in changes in plant growth, and significantly affected the amount of damage caused by the herbivores, total plant biomass did not respond as expected under the adaptive plasticity hypothesis (Dudley and Schmitt 1996; Schmitt et al. 1999), as we could not find a significant induction $\times$ herbivory interaction effect. However, we propose that the differences observed in our study (e.g., reduced ramet production rates and shorter petioles in the cost experiment, decreased amount of leaf damage in the benefits experiment) are likely to translate into substantial differences in plant productivity, and hence biomass, in the longer term.

\section{Costs of SIR}

\section{Biomass production and allocation}

Total plant biomass production did not change as a consequence of defense induction, implying that defense induction did not incur direct and immediate productivity costs. After induction, however, biomass allocation shifted significantly towards the leaves. We suggest that this allocation shift may enable plants to better cope with current and future herbivory by reducing resource allocation to those organs that are not currently impacted by herbivore damage. While potentially beneficial in the short term, this response might result in longer term indirect costs due to reduced performance under certain environmental conditions, such as drought, root herbivory and severe root competition. A similar shift in the biomass allocation pattern was observed in Lepidium virginicum plants after defense induction. Induced plants grown at a high density showed a reduction in root biomass and an increase in aboveground biomass (Agrawal 2005). In agreement with our findings, total biomass production was not significantly altered by defense induction in that study. A reduction in belowground biomass was also reported for

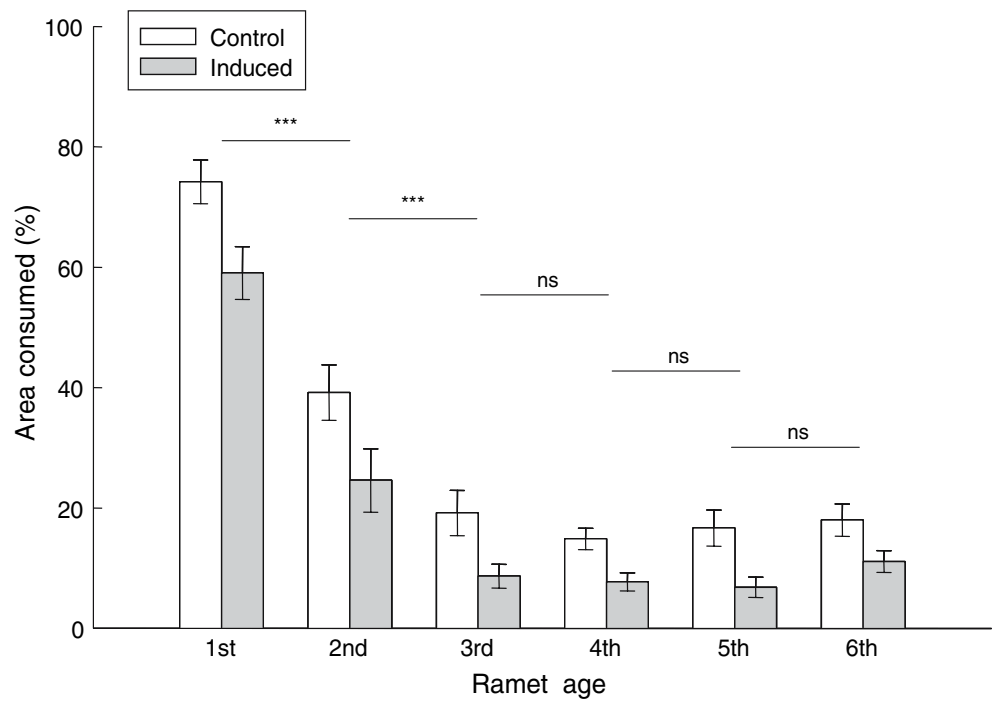

Fig. 2 Average damage $( \pm 1$ SE) inflicted on ramets of the main stolon (the 1st ramet being the youngest and the 6th being the oldest) of control and induced plants in the competition tray after carrying out a controlled herbivore attack (herbivory treatment). Damage categories: no damage (0), $1-33 \%$ (1), 33-66\% (2), 66-100\% (3). The asterisks above the bars indicate the statistical significance of the result of a profile analysis (SAS procedure GLM; profile statement) to test for differences in the degree of damage between ramets of successive age classes. The amount of damage was significantly higher for control than for induced plants in all age classes. $* * * P<0.001, n s$ not significant 
induced wild parsnip plants. In this case, however, the aboveground biomass did not change significantly after defense induction (Zangerl et al. 1997). Further studies are necessary to assess the generality, functional significance (including costs and benefits) and mechanistic basis of changes in root-shoot allocation in response to induced resistance to herbivory.

\section{Reduction in developmental growth rate}

Defense induction negatively affected plant fitness by reducing the number of ramets produced. This delayed developmental growth rate was expressed as a reduction in the number of ramets on the main stolon produced during the experiment ( 7.4 ramets on the control and 7.0 on the induced plants). In the shorter run (i.e., time span of this experiment) this effect is unlikely to translate into biomass differences. In the longer run, however, subtle changes in the developmental growth rate are known to result in very major divergences in performance, structure and clonal fitness of stoloniferous plants (Birch and Hutchings 1992a; Birch and Hutchings 1992b; Huber and Stuefer 1997; Stuefer and Huber 1998).

\section{Reduction in petiole length}

Defense induction had significant negative effects on petiole lengths. This effect can have severe performance and fitness consequences for a stoloniferous plant like T. repens, which often grows in dense herbaceous canopies, and which relies on petiole elongation for shade avoidance (Huber 1997). Petiole length largely determines the ability of stoloniferous plants to place their leaves higher up in the canopy (Huber and Wiggerman 1997; Weijschedé et al. 2006). Even a small reduction in petiole length could have serious performance costs since differences in the relative position of leaves in herbaceous canopies are likely to be amplified by asymmetric competition for light (Weiner 1990; Pierik et al. 2003). Defense induction may also cause physiological trade-offs which impede the simultaneous expression of plasticity to herbivores and to shading by competitors (Cipollini 2004). A decrease in petiole length as a result of defense induction can hence, compromise the competitive ability of plants and result in an enhanced risk of induced plants being over-shaded by neighbors. A recent study by Kurashige and Agrawal (2005) supports this notion by showing that Chenopodium album plants, which had previously been damaged by herbivores, were able to elongate stems to a similar proportional degree as undamaged plants when grown in competition for light. However, the damaged plants were smaller due to the expression of induced resistance, thereby incurring potential opportunity costs due to asymmetric competition.
Benefits of SIR

\section{Reduced damage}

Our results provide direct evidence for short-term benefits of having an early-warning system in clonal plant networks. In the presence of herbivores, induced plants suffered considerably less damage than control plants. As many as $50 \%$ fewer ramets were attacked in induced plants as compared to controls. Localized damage (defenseinduction treatment) resulted in a greater degree of protection against herbivores for ramets further along that main stolon and its side branches. The reduced damage did not translate into a significant effect of defense induction on biomass production, due to the fact that the youngest, usually not fully developed leaves were heavily preferred by the herbivores. The biomass loss due to young leaf consumption is very likely to strongly underestimate the negative effects of herbivory and defense induction on future plant growth and performance. Coleman and Leonard (1995) demonstrated how leaf area consumption, and its consequences for plant performance, can be severely underestimated if the developmental stage of leaves is not taken into account. They showed that a certain amount of damage inflicted on young expanding Nicotiana tabaccum leaves is more detrimental than the same amount received by mature, fully developed leaves. As leaf tissue expanded, the area of the holes increased almost fourfold and the final area of the leaf decreased by approximately $40 \%$. In addition, they observed a 35\% decrease in the number and mass of fruits on the plants that received the damage to expanding young tissues. Therefore, an initially small amount of damage inflicted on young developing leaves may have dramatic consequences for plant performance and fitness over time. Similarly, the differences found in our experiment can be expected to result in considerable performance differences between induced and uninduced plants as increased damage and loss of young leaves in uninduced plants will compromise plant productivity by reducing the number of future source ramets.

Our results show that ramet age largely determines herbivore damage. The first and second ramets were heavily attacked as compared to the rest. This damage, although still large, was significantly reduced in induced plants. The reduction in leaf area loss in induced young ramets likely increases their chance of survival and establishment. Young ramets in clonal plants constitute the most valuable tissue since they represent the future reproductive potential of the plant (Huber and During 2000) and their protection is critical since they are responsible for a high proportion of the future biomass production (Beinhart 1963). We present evidence supporting the hypothesis that an early-warning system after herbivory in a clonal plant 
network grants vulnerable young offspring ramets with parental support (Stuefer et al. 2004) that non-clonal plants are unable to confer their offspring at the moment of the attack (but see Agrawal et al. 1999).

Our study provides evidence for significant costs and benefits of systemic defense induction in $T$. repens. The experimental approach used in this study, however, does not allow for balancing costs and benefits in terms of plant fitness and overall plant performance, because both positive and negative effects of induction reported here, although likely to have significant longer-term effects on productivity and ultimately on fitness, did not have an effect on biomass at the short time scale during which the experiment took place. While our results indicate clear advantages and disadvantages of network induction in the subsequent presence and absence of herbivores, respectively, an accurate and reliable quantification of the costbenefit ratio should make use of long-term experiments.

In conclusion, the present study shows that in the short term, the activation of early-warning responses in clonal plant networks has both costs and benefits. In the absence of herbivores, the performance of the induced phenotype was compromised as compared to the uninduced phenotype in terms of potential competitive ability. In the presence of herbivores, the induced phenotype was favored by suffering considerably less herbivore damage suggesting potential advantages for the phenotype correctly matching its environment. Whether this represents an adaptive value of the induced responses remains to be demonstrated in longer-term studies where the initial small changes observed in our study can be measured directly in terms of fitness. The long-term balance of costs and benefits of induced resistance in clonal plant networks is likely to be strongly context dependent and a function of the match between spatio-temporal aspects of systemic defense expression and the feeding behavior of herbivores.

Acknowledgements We thank P. Walker, C. Jansen, T. van Mölken, H. de Caluwe, X. Chen, J. Weijschedé, A. Smit-Tiekstra, P. Rodersman and T. Koubek for practical assistance, and H. de Kroon, T. van Mölken, and N. van Dam for useful comments on a previous version of this manuscript. This study was funded by the Netherlands Organization for Scientific Research (NWO, VIDI fellowship to J. F. S.). V. L. was funded by the Czech Science Foundation, grant no. 206/03/H034.

\section{References}

Agrawal AA, Strauss SY, Stout MJ (1999) Costs of induced responses and tolerance to herbivory in male and female fitness components of wild radish. Evolution 53:1093-1104

Agrawal AA (2000) Benefits and costs of induced plant defense for Lepidium virginicum (Brassicaceae). Ecology 81:1804-1813

Agrawal AA (2005) Future directions in the study of induced plant responses to herbivory. Entomol Exp Appl 115:97-105
Alpert P (1996) Nutrient sharing in natural clonal fragments of Fragaria chiloensis. J Ecol 84:395-406

Alpert P, Stuefer JF (1997) Division of labour in clonal plants. In: de Kroon H, van Groenendael J (eds) The ecology and evolution of clonal plants. Backhuys, The Netherlands, pp 137-154

Baldwin IT (1998) Jasmonate-induced responses are costly but benefit plants under attack in native populations. Proc Natl Acad Sci USA 95:8113-8118

Beinhart G (1963) Effects of environment on meristematic development, leaf area, and growth of white clover. Crop Sci 3:209213

Bergelson J (1994) The effects of genotype and the environment on costs of resistance in lettuce. Am Nat 143:349-359

Bergelson J, Purrington CB (1996) Surveying patterns in the cost of resistance in plants. Am Nat 148:536-558

Biere A, Marak HB, van Damme JMM (2004) Plant chemical defense against herbivores and pathogens: generalized defense or tradeoffs? Oecologia 140:430-441

Birch CPD, Hutchings MJ (1992a) Stolon growth and branching in Glechoma hederacea L.- an application of a plastochron index. New Phytol 122(3):545-551

Birch CPD, Hutchings MJ (1992b) Analysis of ramet development in the stoloniferous herb Glechoma heredacea using a plastochron index. Oikos 63(3):387-394

Cipollini D (2004) Stretching the limits of plasticity: can a plant defend against both competitors and herbivores? Ecology 85(1):28-37

Coleman JS, Leonard AS (1995) Why it matters where on a leaf a folivore feeds. Oecologia 101:324-328

Dudley SA, Schmitt J (1996) Testing the adaptive plasticity hypothesis: density-dependent selection on manipulated stem length in Impatiens capensis. Am Nat 147:445-465

Elle E, Van Dam NM, Hare JD (1999) Cost of glandular trichomes, a "resistance" character in Datura wrightii Regel (Solanaceae). Evolution 53:22-35

Gómez S, Stuefer JF (2006) Members only: induced systemic resistance to herbivory in a clonal plant network. Oecologia 147:461-468

Heil M, Baldwin IT (2002) Fitness costs of induced resistance: emerging experimental support for a slippery concept. Trends Plant Sci 7:61-67

Herms DA, Mattson WJ (1992) The dilemma of plants-to grow or defend. Q Rev Biol 67:283-335

Huber H (1997) Architectural plasticity of stoloniferous and erect herbs in response to light climate. Utrecht University, Utrecht, The Netherlands

Huber H, During HJ (2000) No long-term costs of meristem allocation to flowering in stoloniferous Trifolium species. Evol Ecol 14:731-748

Huber H, Stuefer JF (1997) Shade-induced changes in the branching pattern of a stoloniferous herb: functional response or allometric effect? Oecologia 110:478-486

Huber H, Wiggerman L (1997) Shade avoidance in the clonal herb Trifolium fragiferum: a field study with experimentally manipulated vegetation height. Plant Ecol 130:53-62

Hurlbert SH (1984) Pseudoreplication and the design of ecological field experiments. Ecol Monogr 54:187-211

Kurashige NS, Agrawal AA (2005) Phenotypic plasticity to light competition and herbivory in Chenopodium album (Chenopodiaceae). Am J Bot 92:21-26

Marshall C (1990) Source-sink relations of interconnected ramets. In: van Groenendael J, de Kroon $\mathrm{H}$ (eds) Clonal growth in plants: regulation and function. SPB, The Hague, pp 23-41

Pierik R, Visser EJW, De Kroon H, Voesenek LACJ (2003) Ethylene is required in tobacco to successfully compete with proximate neighbours. Plant Cell Environ 26:1229-1234 
Pitelka LF, Ashmun JW (1985) Physiology and integration of ramets in clonal plants. In: Jackson JBC (ed) Population biology and evolution of clonal organisms. Yale University Press, New Haven, Conn., pp 399-435

Potvin CM, Lechowicz J, Tardif S (1990) The statistical analysis of ecophysiological response curves obtained from experiments involving repeated measures. Ecology 71:1389-1400

Sagers CL, Coley PD (1995) Benefits and costs of defense in a neotropical shrub. Ecology 76:1835-1843

Schmitt J, Dudley SA, Pigliucci M (1999) Manipulative approaches to testing adaptive plasticity: phytochrome-mediated shade-avoidance. Am Nat 154:43-54

Siemens DH, Lischke H, Maggiulli N, Schurch S, Roy BA (2003) Cost of resistance and tolerance under competition: the defensestress benefit hypothesis. Evol Ecol 17:247-263

Strauss SY, Rudgers JA, Lau JA, Irwin RE (2002) Direct and ecological costs of resistance to herbivory. Trends Ecol 17:278285

Stuefer JF, Gómez S, Van Mölken T (2004) Clonal integration beyond resource sharing: implications for defence signalling and disease transmission in clonal plant networks. Evol Ecol 18:647667

Stuefer JF, Huber H (1998) Differential effects of light quantity and spectral light quality on growth, morphology and development of two stoloniferous Potentilla species. Oecologia 117:1-8

Van Dam NM, Baldwin IT (1998) Costs of jasmonate-induced responses in plants competing for limited resources. Ecol Lett 1:30-33

Van Dam NM, Baldwin IT (2001) Competition mediates costs of jasmonate-induced defences, nitrogen acquisition and transgenerational plasticity in Nicotiana attenuata. Funct Ecol 15:406415

Weiner J (1990) Asymmetric competition in plant populations. Trends Ecol 5:360-364

Weijschedé J, Martinkova J, De Kroon H, Huber H (2006) Shade avoidance in Trifolium repens: costs and benefits of plasticity in petiole length and leaf size. New Phytol 172:655-666

Zangerl AR, Arntz AM, Berenbaum MR (1997) Physiological price of an induced chemical defense: photosynthesis, respiration, biosynthesis, and growth. Oecologia 109:433-441 